\title{
Papillary carcinoma in a giant lateral thyroglossal cyst
}

\author{
S.N. Banerjee, N. Ananthakrishnan, A.J. Veliath and C. Ratnakar \\ Jawaharlal Institute of Postgraduate Medical Education and Research, Pondicherry 605 006, India.
}

\begin{abstract}
Summary: The development of carcinoma in a thyroglossal cyst is rare. This report describes the presence of papillary carcinoma in a giant thyroglossal cyst and reviews the literature regarding the clinico-pathological features of the disease and its management.
\end{abstract}

\section{Introduction}

The thyroid gland develops from the base of the primitive tongue at the foramen caecum, as an outpouching which extends inferior to the cricoid. The thyroglossal duct tract is subsequently obliterated by the sixth week of intrauterine life (Nathanson, 1976). Thyroglossal cysts which arise from the remnants of the duct contain thyroid tissue which can undergo malignant transformation.

\section{Case report}

A 45 year old woman presented with a large $(24 \times 12 \mathrm{~cm})$ cystic swelling in the neck of 8 months duration, with a rapid increase in size over the last 6 months (Figure 1). The swelling had commenced in the midline and had extended to the right side of the neck. There were no symptoms of pressure or altered thyroid function. There was no past history of irradiation to the head and neck. The swelling did not appear to move with deglutition. The thyroid gland was not palpable and there were no palpable lymph nodes in the neck.

An ultrasound examination of the swelling revealed a large cystic mass with some particulate material. Indirect laryngoscopy showed normal mobility of both vocal cords.

At operation, a large cyst containing about $1000 \mathrm{ml}$ of brownish fluid, adherent to the internal jugular vein and the strap muscles, was found. The cyst was separate from the thyroid which was normal except for a hard nodule $1 \mathrm{~cm} \times 1 \mathrm{~cm}$ in the right lobe. Since there was a suspicion of malignancy in the thyroid, a right hemithyroidectomy was performed along with excision of the cyst which was densely adherent to the midline in the region of the hyoid bone, though no definite thyroglossal duct could be demonstrated. The

Correspondence: S.N. Banerjee, M.S.

Accepted: 10 February 1986 cut section of the cyst showed a papillary growth $3 \times 2 \mathrm{~cm}$ arising from the cyst wall (Figure 2).

Histological examination of the cyst wall revealed features suggestive of a thyroglossal cyst and that of the papillary growth revealed papillary carcinoma. There was no focus of malignancy in the excised lobe

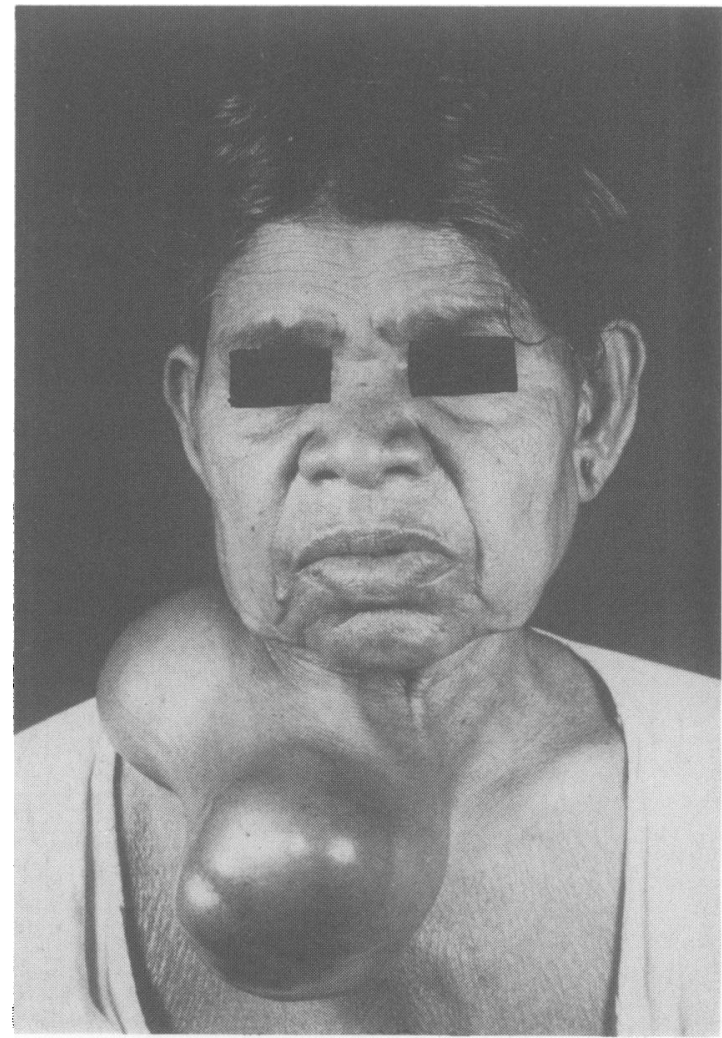

Figure 1 Clinical photograph with large lateral thyroglossal cyst.

C The Fellowship of Postgraduate Medicine, 1986 


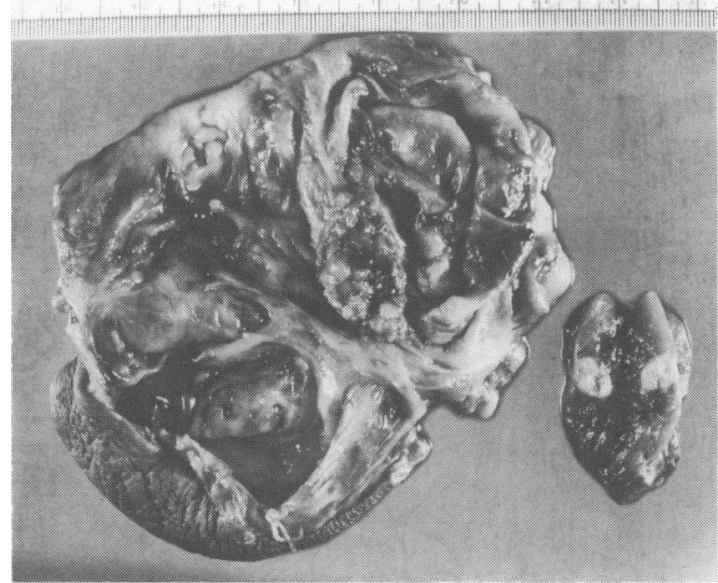

Figure 2 Excised specimen slit open to show the smooth lining and the intracystic papillary growth. The excised right lobe of the thyroid with a well defined nodule is also seen. This nodule on histology showed haemorrhage with calcification.

of the thyroid, the hard nodule revealing haemorrhage with calcification (Figures 3 and 4).

The patient was started on thyroxine postoperatively and advised follow-up.

\section{Discussion}

Carcinoma arising in a thyroglossal cyst on a thyroglossal duct remnant is rare, with an estimated incidence of less than $1 \%$ (Li Volsi et al., 1974). Fewer

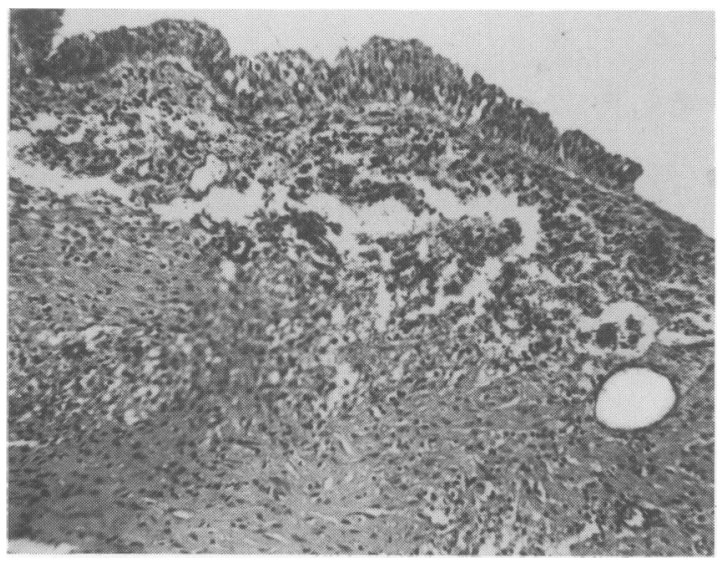

Figure 3 Photomicrograph showing cyst wall lined by columnar epithelium $(\mathrm{H}$ and $\mathrm{E} \times 165)$.

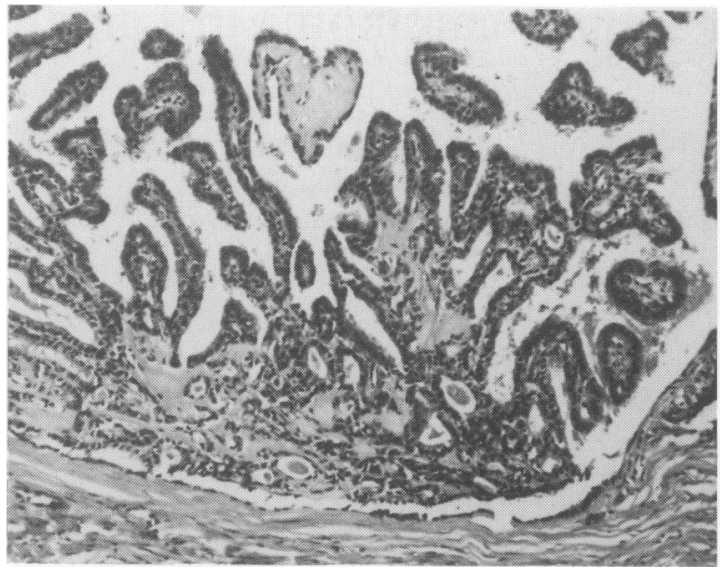

Figure 4 Photomicrograph showing the fronds of papillary carcinoma in the thyroglossal cyst wall $(\mathrm{H}$ and $\mathrm{E} \times 165)$.

than a hundred cases have been reported (Stone \& Milm, 1976; Saharia, 1975; Roses et al., 1983). Histologically, $90 \%$ of these have been papillary, the remainder being follicular, squamous cell or anaplastic (Li Volsi et al., 1974). Most cases are thought to arise de novo from the cyst wall, though in some cases there is a history of external irradiation to the head and neck, which is reported to enhance the development of carcinoma in the thyroid (Roses et al., 1983).

In this case, there was pathological evidence for the presence of a thyroglossal cyst, with its epithelium and the presence of thyroid tissue in the cyst wall. The papillary carcinoma was found to arise from the cyst wall. The absence of any focus of carcinoma in the thyroid, as in this case, was once considered as a prerequisite for the diagnosis (Saharia, 1975). However, studies of excised thyroids in such cases have revealed that up to $25 \%$ exhibit another focus of papillary carcinoma (Nathanson, 1976), emphasizing the multicentric nature of the tumour. A rapid increase in the size of a thyroglossal cyst which subsequently was found to contain carcinoma has been reported in some cases (Roses et al., 1983). This was also a feature of the present case; however, the giant thyroglossal cyst is an unusual presentation.

Almost all cases of thyroglossal cysts with papillary carcinoma have been diagnosed only by histopathology. Local excision of the cyst with postoperative thyroxine therapy is probably adequate in most cases. However, if the thyroid scan reveals cold areas, the tumour arises adjacent to the pyramidal lobe region of the thyroid or there is a history of irradiation to the 
head and neck, thyroidectomy has to be considered (Roses et al., 1983). Lymph nodal metastases are rare and these patients almost never die of this disease (Jaques et al., 1970). One patient with distant metastases from this tumour has been reported (Maxwell \& Marchetta, 1960). However, the prognosis of this lesion appears to be very favourable, especially if it is

\section{References}

JAQUES, D.A., CHAMBERS, R.G. \& OERTEL, J.E. (1970). Thyroglossal duct carcinoma: a review of the literature and addition of eighteen cases. American Journal of Surgery, $120,439$.

LI VOLSI, V.A., PERZIN, K.H. \& SAVETSKY, L. (1974) Carcinoma arising in median ectopic thyroid (including thyroglossal duct tissue). Cancer, 34, 1303.

MAXWELL, W.C. \& MARCHETTA, F.E. (1960). Papillary adenocarcinoma of the thyroglossal duct tract. Archives of Surgery, 80, 224.

NATHANSON, S. (1976). Carcinoma in thyroglossal duct diagnosed incidentally at the time of surgery (Jaques $e t$ al., 1970; Saharia, 1975; Roses et al., 1983).

The interesting features of the case include a short duration with rapid growth, the very large size of the lesion and its lateral position as opposed to the common midline or paramidline cysts.

cysts: a review. Transactions of the American Academy of Ophthalmology and Otolaryngology, 82, 571.

ROSES, D.F., SNIVELY, S.L., PHELPS, R.G., COHEN, N. \& BLUM, M. (1983). Carcinoma of the thyroglossal duct. American Journal of Surgery, 145, 266.

SAHARIA, P.C. (1975). Carcinoma arising in thyroglossal duct remnant: case reports and review of the literature. British Journal of Surgery, 85, 286.

STONE, A.R. \& MILM, D.C. (1976). Thyroglossal cyst carcinoma. Case presentation and a review of normal thyroglossal cysts. British Journal of Clinical Practice, 42, 773. 